\title{
Dark Cities: A dark tourism index for Europe's tourism cities, based on the analysis of DMO websites
}

Raymond Powell, University of Greenwich, UK

James Kennell, University of Greenwich, UK

Christopher Barton, University of Kent, UK

\section{Purpose}

Dark tourism is a topic of increasing interest, but it is poorly understood when considering its significance for mainstream and commercial tourism. This paper investigates the significance of dark tourism in the top ten most visited European tourist cities and proposes a dark tourism index for Europe’s tourism cities.

\section{Methodology}

Data was collected from the websites of the cities’ Destination Management Organisations (DMOs) using a content analysis methodology, based on keywords related to dark tourism taken from the research literature in this area. Descriptive statistics were produced and the variance between the frequencies of keywords related to each city was analysed for statistical significance. These results were then used to construct a darkness ranking of the cities.

\section{Findings}


There are significant differences in the extent to which dark tourism products and services are promoted by the DMOs of Europe's top ten most visited European cities. The ranking of cities by darkness does not correspond to the ranking by visitor numbers, and further qualitative analysis suggests that that the ranking is also independent of the actual presence of dark sites within the destination. This implies that European city DMOs are engaging with the emerging dark tourism market with to varying degrees.

\section{Research Limitations}

The purposive sample of ten cities can be extended in future research to increase the validity of the findings of this paper. A further limitation is the selection of keywords for content analysis, which have been developed following the literature review contained below. Future research could develop an extended list of keywords using a systematic review process.

\section{Research Value}

This paper shows that it is possible to create a ranking of tourist cities in terms of their darkness, and that this methodology could be extended to a much larger sample size. This links dark tourism research to the urban tourism literature and also offers possibilities for creating a global ranking that could be used by destinations to judge their success in engaging with the dark tourism market, as well as by tour operators seeking to develop products for the same market.

\section{Key Words}


Dark tourism, cities, Europe, content analysis, urban tourism 


\section{Introduction}

The academic study of dark tourism gathered momentum in the early twenty-first century (Stone 2013), and is reflecting the growing interest of the citizens of postmodern societies in the sites of death and disasters - an interest that needs deeper research to be understood fully. It also reflects the increased sensitivity of the international community to the significance of such events for nations, national identities and the direction of their history. Dark tourism sites offer the opportunity to capture and conserve the "dark" memory of humanity and make it available, through domestic and international tourism, to the wider public. It should also be noted that vicarious thrill seeking and entertainment motivations are also significant factors that have affected the recent growth of the dark tourism sector. This study of dark tourism in an urban setting, therefore, offers the opportunity to investigate the many ways in which dark tourism offerings are packaged and presented as tourism products within a significant sector of the tourism industry. This paper aims to investigate this in the context of European city tourism and to construct an index of Europe's top tourism cities in terms of the 'darkness' of their tourism offer.

\section{Dark Tourism}

Dark tourism can be defined as tourism associated with the visitation of sites which have death, tragedy or suffering as an ingredient in the mix of visitor motivations in some way or other. Stone (2005) considers dark tourism to be an old concept in a new world. That is to say that the fascination with scenes of death and disaster are old and quite possibly universal, but what is new is the way in which there is a commercialised and functional tourism industry able to make very much more available to very many more people than was the case in the 
past. The definition of dark tourism is wide and varied. Smith (1998) argues that sites associated with war probably attract more visitors than any other single type of attraction. Dark tourism is a widespread and growing reality and it is an important factor when considering the supply and demand of sites and attractions. Lennon and Foley (1996) described the phenomenon of death related activity and coined the term "dark tourism" to describe this observable and growing trend. Yan et al (2016) review a range of defintions and sub-defintions of this tourism activity and conclude that the phrase 'dark tourism' itself is the most frequently applied term to describe it. Seaton (1996) described the same experience as “thanotourism”, acknowledging that it is not solely a recent occurrence, but has, in fact, ancient precedent. Blom (2000) was able to recognise an apparent subset within the motivations of so called dark tourists, and used the term “morbid tourism”.

As interest in the academic study of dark tourism grew, so too did the labels by which it could be known. Rojek (1993) considered phrases such as “disaster tourism”, “black spot tourism" and even "phoenix tourism” to be appropriate to communicate the central idea of dark tourism: it entails visitation to sites associated with death, suffering and tragedy. Commonly such visits are conducted with commemoration, education or entertainment in mind (Stone, 2005), meaning that much dark tourism research has been published within the heritage tourism literature (Yankholmes \& Akyeampong 2010). The attraction of death, disaster and the macabre promises to be a significant factor in the tourism sector worldwide, and in Europe in particular. Dark tourism offers the interested participant the chance to "gaze upon real or recreated death" (Stone, 2005: 3.) The fascination with scenes of tragedy is not unique to any one set or group of tourists, but dark tourism, as yet, remains on the fringes of respectability: a number of authors have given consideration to "shades" of dark tourism (Lennon and Foley, 2000; Stone, 2005; Strange and Kempa, 2003) which is to say that it is 
recognised that there is a continuum of "dark" touristic experiences, ranging from very mild excitation to the grim reality of the holocaust and terrorism, for example. It is often observed in the literature that dark tourism has a continuum of darkness (see fig 1 below).

At the darkest end of that continuum, attractions are categorised largely on the basis of real, recent and actual suffering and death. There is often an educational and commemorative rationale which underpins the establishment of an attraction, very often being the authentic site of the suffering which is visited, such as at Auschwitz or the site of the Twin Towers in New York. Stone (2006) recognises that the connection with dark tourism at particular sites is fluid, and the relative darkness of each attraction lies along a continuum, ranging from the very dark (Auschwitz, for example) to the commodified, entertainment based attraction, such as the London dungeon which represents gruesome torture as family entertainment. Europe has an abundance of dark tourism sites, both real and imagined which offer ample opportunities to experience dark tourism in all of these ways if so desired. However, they are rarely conceptualised as dark products, and as such categorisation of individual attractions is, at the moment, confused. This also means that whilst dark tourism is proving to be an effective draw for significant numbers of tourists, many sites are not considered in this dark context, and as such opportunities for capitalisation and exploitation of a valuable tourism resource are often overlooked.

Lennon and Foley (2000) have largely been credited with coining the phrase "dark tourism" in "Dark Tourism: The Attraction of Death and Disaster" They sought to signify what they identified as a "fundamental shift in the way in which death, disaster and atrocity are being handled by those who offer associated tourism 'products' "(p3). In doing so, they identified that dark tourism as it is presented in a modern context is the product of the late modern 
world, and is intimately connected to the political, sociological, economic and technological landscape within which modern tourism products are made available. That is to say, whilst death and disaster have always had a universal appeal, the circumstances of modern media, accessibility and technology mean that interest in dark sites is at an unprecedented level, and the tourism industry should be capable of making every effort to provide a product which meets the demand for such dark experiences. The increasing consumerism of post-modern western societies has a tendency towards making such experiences much more entertainment based. Lee et al (2012: 76) highlight the ‘tacit moral opposition’ between dark tourism and 'light' tourism, with their negative and positive conations in terms of the motivations and values of the experiences involved, explaining how it possible, for example, for the relatives of the bereaved to visit sites of disaster to remember loved ones, or for non-dark tourists to admire architecturally significant buildings associated with dissonant heritage (Lemelin et al 2013), without enjoying places of tragedy and death in a vicarious manner. Taylor (2006) examines tourism marketing in destinations that have recently suffered terrorist attacks and shows how DMOs can promote tourism in the wake of an atrocity through marketing campaigns which aim to support local visitor economies, leading to tourism that is associated with 'dark' sites, but which is not easily categorised as dark tourism when it does not involved 'dark' motivations.

The concept of dark tourism however is not a new one. Tourists have been drawn to battlefield sites, places of execution, tombs and other related sites for a very long time (Stone, 2005). Seaton (1996) has identified dark tourism as being the visitation of sites associated with death and disaster, something which dates from the Middle Ages at least. Dale and Robinson (2011) also identify Dark Tourism as being an established practice as far back as the Eleventh Century. It is possible to argue that dark tourism as an actuality was established 
in ancient times: a compelling thought if we consider the popularity of Roman Gladiatorial contests, for example. Collins-Kriener (2016: 1186) examines the concept of dark tourism alongside the more ancient idea of pilgrimage, noting that 'both dark tourism and pilgrimage emerge from the same milieu to include the sites of dramatic historic events that bear extra meaning.' The metaphor of modern pilgrimage has been used to describe the motivations of non-religious dark tourists, as for example in the work of Winter (2011) who explored motivations for tourism to First World War battlefield sites in Belgium. This conceptualisation removes dark tourism from its solely ‘thanatourism’ (Seaton 1996) roots as being linked to death and instead attaches it to a broader trend in visitation to sites of historical significance, some of which will be dark but, for example in the case of pilgrimage, some will be associated with rituals of joy and thanksgiving. Historically it can be seen that tourism has always had aspects of dark tourism in its gaze (Stone 2012).

Several commentators (Lickorish and Jenkins, 1997; as cited in Lennon and Foley, 2000; Vellas and Becherel, 1995) have identified that pilgrimage is one of the earliest forms of tourism. Pilgrimage sites are often associated with death in one form or another, with religious pilgrims often visiting the site of the death, or the graves of individuals or groups. Such visits tend to have religious or spiritual associations relevant to the pilgrims visiting, and are seen as acts of remembrance, commemoration or veneration, and usually feature as part of a ritualistic or tokenistic ceremony, perhaps tied to a particular religious or even secular calendar. It is clear that such ritualistic approaches to commemoration are not solely the stuff of sanitised tourism products within the remit of the modern tourism industry. It should be recognised that there is an increasing demand for dark tourism products which offer a connection with scenes of suffering and death. That is not to say that this is a completely modern phenomenon: visitation to scenes associated with death in particular; 
battlefields, graveyards and the former homes of dead celebrities for example, have proven to be a significant motivator in tourism in past-times as well. However, of particular significance to this study is the consideration of the commodification of such sites has transformed the tourism industry in such a way as to generate demand for, as well as access to, dark tourism experiences. Shondell Miller \& Gonzalex (2013) also discuss ‘death tourism', an emerging field of travel associated with assisted dying, which despite its superficially specific features, can be classified within the spectrum of dark tourism experiences. The growth of a new form of tourism associated with a new set of social or cultural practices or technologies is a regular feature of the development of modern tourism (Poon 1994) and Stone (2013) observes that 'dark tourism is simply a fascinating and controversial area' and therefore the growth in recent scholarship in this field may be attributable to the nature of the subject matter as much as to any specific maturation in the field of tourism studies or developments in the industry itself.

Much of tourism can be seen to be related to classic demand/supply issues: does demand drive supply or does supply initiate demand? The nature of dark tourism is multi-faceted, and despite its increasing popularity, understanding of the phenomenon remains limited (Biran et al, 2011). Yan et al (2016: 110) split their definition of dark tourism into two categories; that which is focused on a psychological consumption process and which 'offers tourists desired psychological outcomes and actual psychological outcomes to satisfy tourists' emotional demands' and that which is focused on the supply-side of dark tourism and which 'supplies emotional and cognitive experiences to tourists who have an interactive relationship with a dark tourism product, including either man-made or natural disaster destinations.' Biran et al (2011) see little distinction between dark tourism and heritage tourism, however. They argue that dark tourism is largely a product of supply side factors, and as such visitation to 
Auschwitz-Birkenau (the case study under consideration by them) needs further examination of visitors' perceptions must be considered in order to fully understand the complex motivations of such visitors, and it is unlikely to be simply a morbid fascination with death alone which encourages current annual visitation of over 1.7 million people (Times Of Israel 2016). This notion challenges the descriptive idea that dark tourism is simply about death and disaster to an approach which must necessarily encourage the exploitation of dark attractions in line with other, similar heritage attractions. The core motivations in this case are seen as essentially those of heritage tourists with the dark aspect being an addition rather than a prime motivator.

Famaki (2013) suggests that dark tourism in general appears to be supply driven and attraction based, but a segmented approach to marketing such attractions which takes into consideration the purpose of the visit with regard to personal considerations and the relevance of the dark site to the individual tourist and the depth of the dark element all combine to make a clear exposition of dark tourism motivations difficult to ascertain. It seems likely that there are a variety of motivations, but nonetheless there are a number of drivers which dark tourism destinations can be better placed to exploit. The significance of that observation for this work is that dark attractions will prove appealing and are likely to increase overall visitation in an urban context especially, where there are also other pull factors encouraging tourists to visit in addition to the dark attractions alone. Over 3.5 million visitors visited the Ground Zero site in New York in 2007, marking it out as one of the biggest visitor attractions in the city (Kang et al, 2012). It seems unlikely that all of those 3.5 million visitors were visiting New York exclusively to visit Ground Zero, and it seems reasonable, therefore, to speculate that dark tourism is an additional motivation to visit urban environments when there are a range of pull factors at play (Crompton, 1979) to entice and encourage visitation. Rural locations, however, 
also have the potential to offer resources for the dark tourism market, whether these are the now-empty battlefield sites of Scotland (Banks \& Pollard, 2011), the 'rural dystopias' of post-agricultural Australia (Rofe 2012) or the haunted castles of Transylvania (Light 2017).

Stone (2006) offers a categorisation of the supply-side of dark tourism into seven 'dark suppliers': Dark Fun Factories - those sites which are primarily focussed on entertainment, with low levels of authenticity; Dark Exhibitions - dark tourism products that blend entertainment and learning opportunities, often with a commemorative or reflective intention; Dark Dungeons - which rely on the presentation of sites associated with previously implemented penal codes; Dark Resting Places - based on cemeteries or grave markers; Dark Shrines - these are specially constructed attractions which provide an opportunity to commemorate or remember the recently deceased; Dark Conflict Sites - being sites associated with warfare and Dark Camps of Genocide - sites at the darkest end of the dark tourism spectrum which present locations associated with genocide, atrocity and catastrophe.

Stone (2005) suggests that the supply side aspects of delivering a dark tourism product depend largely on factors such as the attempt to manipulate a dark site for political purposes, or the desire to achieve a commercial advantage. Such factors need, rightly, to be considered with sensitivity, and may prove to be a significant limiting factor in the willingness of DMO’s to develop dark sites fully on a commercial basis. Notwithstanding this consideration, as research develops it is becoming apparent that the typology of dark attractions is varied. Stone’s (2006) work develops the darkness continuum, within which attractions can be considered according to their perceived darkness (fig 1). Miles (2002) proposes a similar model, again through consideration of Auschwitz as a destination, which also has authenticity at the core of the dark offering. That is to say, actual sites of death and disaster exert a 
stronger pull for the visitor. Such authentic sites tend to have commemoration at the core of their offering and tend to be history-centric. This does mean that sites which are authentic have a much greater pull in dark tourism, and as is the case with similar heritage attractions, it does present a unique selling point for DMO's to consider, bearing in mind that visitation is unlikely to involve visitation to the dark site alone for the duration of the stay. Stone (2012, 2013: 307) points out that dark tourism has become an 'increasingly pervasive part of the visitor economy' and refers to the locations of dark tourism experiences as 'deathscapes’. Authenticity with regard to location is a key factor at the darkest end of Stone's (2006) spectrum, but time is also a consideration, as in how much time has elapsed since the actions commemorated at the site. Essentially, the nearer the events are to us in time, the darker they appear. Sites which are near contemporary and located at the actual scene prove to be the darkest of all, and this in turn can influence visitor expectations and experience due to the level of empathy shown by visitors who are aware of a closer connection to dark events, therefore (Miles, 2002). Ryan and Kohli (2016) also argue that temporal, political and ideological factors all have influence on visitor perceptions at a dark attraction. These considerations can partly explain the way in which supply side dark tourism is not keeping pace with demand. However, this paper argues that the potential for dark tourism is often unacknowledged when considerations other than commemoration are brought into the mix. It should be recognised that no study of the supply side of dark tourism is complete without also considering demand led factors (Stone, 2006). 


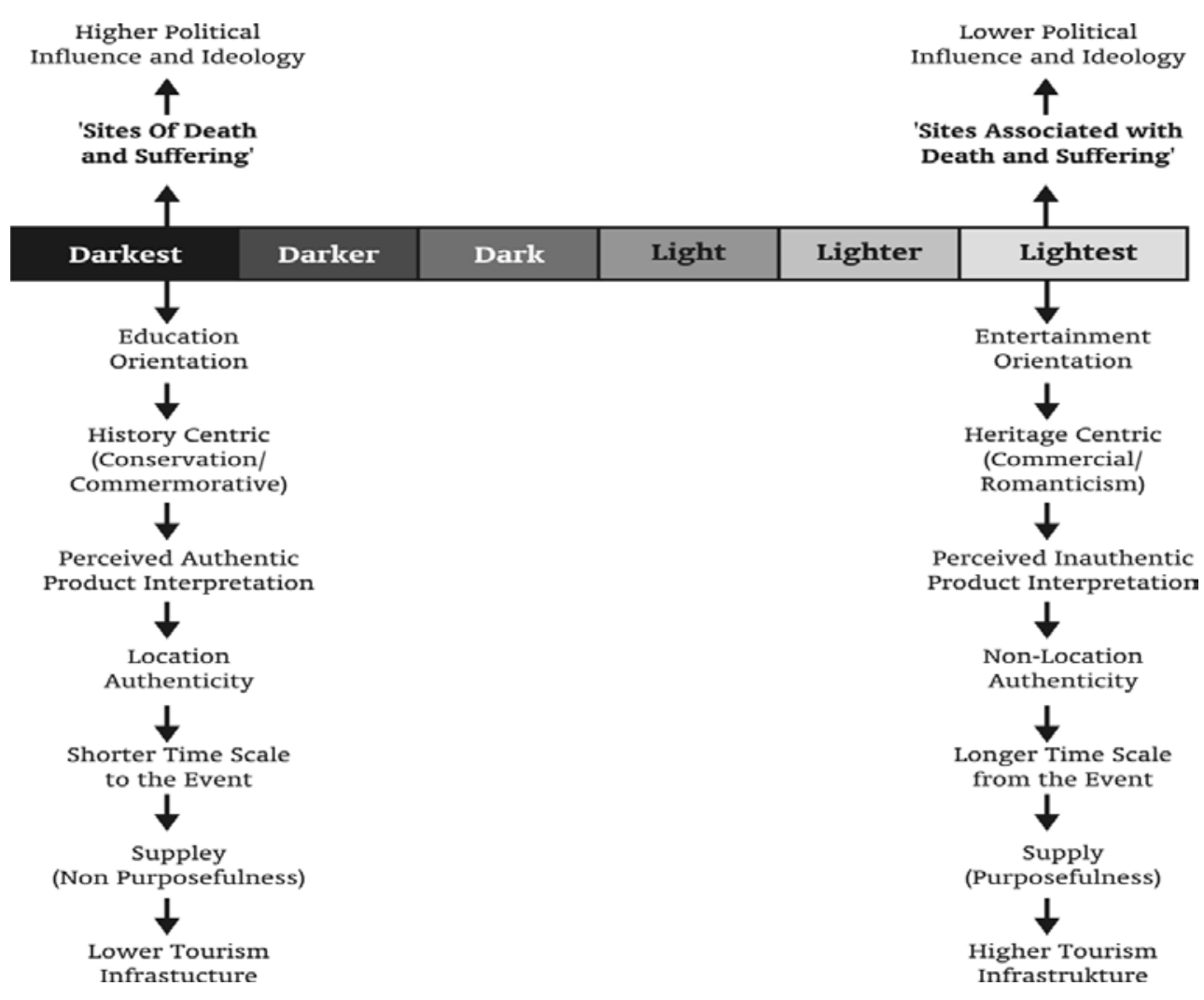

Figure 1 - A Dark Tourism spectrum: perceived product features of Dark Tourism within a “darkest-lightest” framework of supply (Stone, 2006)

The motivations for visiting dark sites is an under-researched area (Sharpley and Stone, 2009), and somewhat beyond the remit of this paper. However, Stone (2005) identifies that the desire to create a mercantile advantage or manipulate a particular site for political reasons are usually the primary supply-side factors which will determine whether a Dark site is developed or not. It should also be noted that a usual explanation for the establishment of Dark sites is that they allow contemplation of one's own death - the memento mori effect (Walter, 2006). Inauthentic offerings allow this contemplation to be at several stages removed, unlike the horror of a death camp for example. There is also a marked reluctance to be seen to be making money from other people’s suffering, and it may be that esoteric questions of taste cloud the development of more authentic dark sites. 
The dark tourism continuum model has been adapted by Raine (2013) to similarly characterise dark tourists in terms of the 'shade' of their motivation, ranging from 'mourners', through the 'morbidly curious' and the sightseers' to 'passive recreationists', although the limited sample size of 23 graveyard visitors means that the typology requires further testing. Researching the motivations of black metal tourists in Norway, Podoshen (2013) identified motivations related to consumption linked to a specific cultural form, suggesting that dark tourism motivations can also be considered from the perspectives of subcultures and media and Podoshen et al (2015) specifically suggest that the application of concepts from outside of mainstream tourism studies such as Consumer Cultural Theory (CCT) to the study of dark tourism motivations may produce yet more sophisticated perspectives on the demand side of the dark tourism phenomenon.

Seaton (1996) argues that visitors to dark sites have as a significant motivation the desire for an actual or symbolic encounter with death, and this underlying motivation needs to be considered in conjunction with the idea that visitors to many dark sites may not always be necessarily aware that the site is, in fact, dark. This is because attractions like museums may not be explicitly marketed as "dark”, but do fit into the continuum of dark attractions as postulated by Stone (2006, fig 1) but which still act as key motivator in actuality, although the draw may be more linked to the idea of "heritage”, as suggested by Famaki (2013). As Rittichainuwat (2008) highlights, motivations for dark tourists can depend on differences in motivations between the very diverse groups who partake in it; children and young people are the most curious group when it come to a general interest in atrocities, for example, whilst women are most likely to show concerns about safety and security when choosing dark tourism destinations. When evaluating the motivations of Scandinavian and domestic-Thai visitors to dark tourism sites in Phuket, Thailand, Rittichainuwat (2008) found significant 
differences in push and pull-factor motivations (Crompton 1979) based on the nationalities of the tourist studied, as well as in their ages. Lee et al (2012), in their study of tourism to the North Korean Mt Kumgang mountain resort, also consider the western-centric perspective of much dark tourism research, suggesting that future research may wish to more effectively distinguish between indigenous and non-indigenous tourism to non-western dark tourism sites. This point is supported by the work of Lemelin et al (2013) who show that the consumption of 'war heritage' sites of significance to indigenous peoples, by dark tourists, can contribute to the perpetuation of 'grand colonial narratives' which reinforce the dominant histories associated with dissonant heritage.

It is, therefore, a key consideration for this paper that dark tourism is a real phenomenon, in that it exists as a motivator for visitation, albeit in ways which are not necessarily fully understood or researched at present. Nevertheless, it is also recognised also that there is significant overlap with dark and other forms of tourism (for example heritage tourism), and in certain cases visitation to dark sites may be coincidental. Seaton and Lennon (2004) identified two key motivators for dark visitation: 1. Shadenfreude (the contemplation of others' misfortune: and 2. Thanatopsis - the contemplation of death. However, it may be that such motivations are considered as an afterthought rather than necessarily primary factors, although Smith and Croy (2005) maintain that all visitors to dark sites are motivated by an interest in death, and it is acknowledged that not all tourists share the same experience. This has significant implications for the marketing of dark attractions, and it could be inferred that currently (with the possible exception of the darkest attractions such as concentration camps) the marketing implications of dark site development needs to be further evaluated and understood more fully. It is a key contention of this paper that often visitors to dark sites may not be aware of the classification of "dark" as being especially relevant to them and their 
leisure activities. However, DMO’s would benefit from identifying suitable dark attractions and making them available to this latent and often untapped market. In other words, if there is more clarity around what an attraction has to offer, it will prove more attractive to visitors and in the case of dark attractions marketed as such will appeal to more visitors potentially. Nevertheless, they are most definitely an integral part of the appeal of dark tourism, and it is that appeal that DMO’s need to recognise and capitalise on in order to attract increased visitation.

It is recognised that commercial or other exploitation of dark sites involves a number of ethical issues. In particular Seaton (2009) points out that there is a general feeling that "it is unacceptable to profit from the dead” (p87). The classic model of visitor attractions would dictate that commercial, and in particular retail operations are an important source of revenue. However, this may prove a contentious area: consider the restraints on merchandise they can offer, limited by both location and subject matter (Brown, 2013). This does mean that DMO’s and other interested parties will need to consider their dark developments carefully: there is an appeal, but if that appeal and increased visitation is difficult to capitalise then it is less likely to happen. Of course, authentic dark sites in particular have merit on their own as attractions, but it is necessary to also consider matters of taste and decency (Sharpley, 2009). This may serve to limit commercial exploitation, but as part of a coordinated approach to visitor management overseen by a DMO or similar it can be a vital part in increasing overall visitation, with the benefits to commercial exploitation perhaps realised elsewhere in other local businesses such as cafes and bars. It is also worth noting that often dark tourism sites are not spatially or temporally distinct or unusual places (Johnson, 2015). For example, Ground Zero in New York is a busy pedestrian thoroughfare, and families regularly picnic in Pierre Lachaise cemetery in Paris. This observation has implications when considering use of 
space: it should be possible to combine multiple uses with careful planning, thus maximising potential within an urban context. In particular, it should be recognised that often Thanatourism sites are not all one-dimensional theme parks created purely for those interested in death. The sites exist in their own right and often serve everyday functions, existing as places were local people live their lives (Johnson, 2015).

\section{Urban Tourism in Europe}

Urban tourism is a challenging and multi-disciplinary field of study that draws on areas including sociology, urban studies, planning and architecture, as well as traditional tourism research (Selby 2004). Research in urban tourism has been prompted by the recent dramatic growth of tourism to cities. Urry (2002) noted that the shift of tourism to urban areas from traditional coastal destinations has accompanied a broader shift within postmodern culture, which prioritises consumption, accessibility, culture and technology, which began in the 1980s. Gale presents Urry's (1994) set of processes that exemplify the postmodern transformation of culture, and therefore tourism. These are based on Harvey's (1989: 340341) categorisations

- Clock time to instantaneous time

- Writing and substance to image and surface meaning

- Occupation and home to consumption and play

- Fordism to post-Fordism

- Globalization to Localization (Gale 2005: 92-93) 
Some implications of this are highlighted:

- Overseas travel (image, status) becomes more desirable

- Overseas travel becomes easier and more affordable due to time-space compression

- 'post-tourists' or 'post-modern tourists' didn’t like the regimented Saturday to Saturday element of traditional holidays (Gale 2005: 94)

- The weakening of group identities and associations affects places designed to service these groupings and offer an alternative to an older form of the collective holiday experience.

- The importance of fashion and taste - older resorts become 'tasteless' (Gale 2005: 93)

By the end of the 1990s, many post-industrial cities were seeking ways of diversifying their economies, and tourism development offered opportunities for investment and promotion (Ben Dalia et al 2013). Hoffman (2003) studies the development of Harlem, New York in the post-Fordist period from the perspective of regulation theory and shows how significant changes in the local economy over a period of thirty years have provided specific opportunities for tourism development in the area. For example, cultural diversity has become a key aspect of marketing in a highly differentiated market place and the area of Harlem can offer products and services that meet the needs of many different cultural segments, as well as the desires of tourists to consume diverse products, leading to a growth in niche tourism products such as cultural tourism which are an example of 'flexible specialisation', a concern of regulationist approaches to understanding post-Fordist economies. Whilst noting that tourism appears to function well as an economic engine for 
urban areas, Gladstone \& Feinstein note that 'the distributional consequences of tourism are more debatable’ (2001: 38).

Urban tourism offers a number of benefits to destinations. Unlike other forms of tourism, it displays little seasonality (Higham \& Luck 2010), attracts relatively well educated and welloff tourists and provides opportunities for niche tourism development such as business tourism (Davidson 1996) and cultural tourism (Richards 2007). Urban tourism is now a core part of urban redevelopment and competitiveness strategies (Richards \& Wilson 2007, Spirou 2007, Smith 2007b, Zukin 1995), but this only serves to reinforce the already central role of tourism and culture in the development and image of urban areas. As Sharon Zukin points out, "For several hundred years, visual representations of cities have 'sold' urban growth. Images, from early maps to picture postcards, have not simply reflected real city spaces; instead they have been imaginative reconstructions - from specific points of view - of a city’s monumentality” (1995: 16). The huge competition between cities, coupled with the growth in accessible transportation and the emergence of new economies into the global economy, has meant that cities that have not historically been well-known tourism destination to enter the tourism industry, leading to increased global completion between cities for urban tourists (Ben Dalia et al 2013). Because of this, it is important for cities to understand areas of the tourism market in which they can offer novel and unique experiences to tourists, to increase their attractiveness - the growing dark tourism market (Biran \& Hyde, 2013; Stone 2005; Stone \& Sharpley, 2008) offers a way for many cities to become more competitive in this sense.

If we define urban tourism simply as tourism that takes place in urban areas, it becomes more important to develop a thorough understanding of the components of urban tourism 
destinations. Selby (2004), in his review of previous writing on urban destinations, includes the following aspects of cities as forming part of the foci of urban tourism research: historic cities, casinos, urban regeneration, major sporting events, visitor management, historic districts, entertainment districts, tourist zones and sacred spaces. Van den Berg et al (1995) describe the five aspects of what they call a 'tourist city’. Firstly, primary products. These are the core reasons why tourists visit a city and can include natural features, historical attributes and specialist tourism facilities such as conference venues, sporting arenas and museums. Next are the secondary products and services, such as accommodation, retail, restaurants and information, which are necessary for generating staying visits, as opposed to day visits in a city. External transport is the third aspect of the tourist city, highlighting the connectivity of the city to tourism-generating regions. The fourth aspect is internal transport: the city must be easily navigable to tourists to ensure that the whole city becomes a resource to tourism, again extending the length of visits. Finally, the tourist city must have a developed tourism image. The image of the city is developed from the relationship of the first four elements to the marketing activates of the city's Destination Management Organisation and the perception of the city held by potential visitors.

An argument of this paper is that dark tourism products form a core part of many cities' tourism offer and that this has not been captured to date in the literature on urban tourism. In terms of Van den Berg et al's description of the tourist city, this paper aims to explore the possibility of dark tourism as a primary product for European cities, with implications for the marketing activities of Destination Management Organisations in the region. 


\section{Method}

In order to assess the significance of dark tourism products in the offering of European tourist cities, a purposeful sample (Bryman \& Bell 2009) strategy was used. An extreme case (Saunders et al 2007) approach was taken to choosing which cities were included in the sample to increase the likelihood that the chosen cities would provide sufficient data on their tourism products to support this initial phase of research. Using the most recently published Euro monitor data for international tourism arrivals (Euromonitor 2017), the following list of the top ten European tourist cities was constructed as the sampling frame for this research. The Destination Management Organisation (DMO) for each city was identified, along with its English-language website. English was chosen as a major lingua franca for international tourists and to ensure that each website was comparable, although this does present a limitation of this research. Each city, its visitor numbers, its DMO and the DMO website are shown in table 1 , below.

Table 1 - Europe's top ten tourist cities

\begin{tabular}{|c|c|c|c|}
\hline City & $\begin{array}{l}\text { Visitors } \\
\text { (millions, } \\
\text { Euromonitor } \\
\text { 2017) }\end{array}$ & $\begin{array}{l}\text { Destination } \\
\text { Management } \\
\text { Organisation }\end{array}$ & Website (English version) \\
\hline London & $18,580.00$ & Visit London & http://www.visitlondon.com/ \\
\hline Paris & $15,023.00$ & Paris Info & http://en.parisinfo.com/ \\
\hline Istanbul & $12,414.60$ & & \\
\hline
\end{tabular}




\begin{tabular}{|c|c|c|c|}
\hline Rome & $9,558.70$ & $\begin{array}{r}\text { Rome } \\
\text { Official } \\
\text { Tourist Site }\end{array}$ & http://www.turismoroma.it/?lang=en \\
\hline Prague & $6,967.40$ & Prague.eu & http://www.prague.eu/en \\
\hline Milan & $6,684.00$ & Visitamilano & http://www.visitamilano.it/turismo_en/ \\
\hline Barcelona & $6,612.20$ & $\begin{array}{c}\text { Barcelona } \\
\text { Turisme }\end{array}$ & http://www.turismedebarcelona.net/ \\
\hline Amsterdam & $5,897.00$ & $\begin{array}{r}\text { I am } \\
\text { Amsterdam }\end{array}$ & http://www.iamsterdam.com/en/visiting \\
\hline Vienna & $5,718.90$ & $\begin{array}{r}\text { Welcome to } \\
\text { Vienna }\end{array}$ & http://www.wien.info/en \\
\hline Venice & $5,490.00$ & $\begin{array}{l}\text { Venice } \\
\text { tourism }\end{array}$ & $\begin{array}{r}\text { http://www.venice-tourism.com/en/visit- } \\
\text { venice.html }\end{array}$ \\
\hline
\end{tabular}

The content of each DMO website was searched using the keywords in table 1, below. A system of keywords was used to categorise the data that refers to themes and concepts of relevance to this research that have been developed in the preceding sections on dark tourism and urban tourism. This is a deductive method of code generation (Berg 2007), that formed a starting point for an inductive process of further categorising the data to allow for the emergence of additional information of relevance to the research. In total, nineteen keywords were identified deductively from the literature reviewed above, with diverse terms chosen and judged for applicability and frequency in the literature, until a theoretical saturation point (van Rijnsover 2017) was reached. Certain terms were then excluded from the list because of their ambiguity, such as 'memorial' and 'historical', which were judged to have too broad an application in DMO promotional material, whilst not retaining a clear focus on tourism products associated with dark tourism. The final list of keywords is shown in table 3, below. 
Table 2 - Keywords used for content analysis

\begin{tabular}{|l|}
\hline Keyword \\
\hline Atrocity \\
\hline Battlefield \\
\hline Catastrophe \\
\hline Commemoration \\
\hline Conflict \\
\hline Dark \\
\hline Death \\
\hline Disaster \\
\hline Dungeon \\
\hline Dying \\
\hline Execution \\
\hline Genocide \\
\hline Holocaust \\
\hline Macabre \\
\hline Monument \\
\hline Pilgrimage \\
\hline Suffering \\
\hline Tragedy \\
\hline War \\
\hline
\end{tabular}




\section{Results}

The data presented by the documents that was analysed according to the categories set out in table three was coded and sorted to allow the construction of descriptive statistics about the data, shown in table four, below.

Table 3 - Content analysis frequency table

\begin{tabular}{|c|c|c|c|c|c|c|c|c|c|c|c|c|}
\hline Code & London & Paris & Istanbul & Rome & Prague & Milan & Barcelona & Amsterdam & Vienna & Venice & Frequency & $\%$ \\
\hline Monument & 865 & 4010 & 50 & 4810 & 2850 & 280 & 1900 & 6740 & 756 & 132 & 22393 & 45.50 \\
\hline War & 2670 & 140 & 648 & 340 & 395 & 161 & 325 & 1100 & 504 & 10 & 6293 & 12.79 \\
\hline Execution & 5140 & 5 & 12 & 16 & 52 & 9 & 90 & 9 & 8 & 1 & 5342 & 10.85 \\
\hline Dark & 829 & 192 & 1170 & 34 & 248 & 36 & 123 & 2140 & 279 & 1 & 5052 & 10.26 \\
\hline Death & 667 & 64 & 616 & 88 & 236 & 107 & 343 & 58 & 821 & 7 & 3007 & 6.11 \\
\hline Dungeon & 2040 & 2 & 1 & 0 & 4 & 0 & 0 & 225 & 0 & 0 & 2272 & 4.62 \\
\hline Dying & 93 & 58 & 605 & 48 & 118 & 71 & 9 & 35 & 673 & 7 & 1717 & 3.49 \\
\hline Pilgrimage & 199 & 10 & 5 & 57 & 52 & 12 & 6 & 956 & 9 & 2 & 1308 & 2.66 \\
\hline Holocaust & 71 & 2 & 1 & 0 & 7 & 6 & 0 & 329 & 5 & 1 & 422 & 0.86 \\
\hline Commemoration & 73 & 4 & 14 & 29 & 200 & 24 & 8 & 21 & 7 & 3 & 383 & 0.71 \\
\hline Conflict & 195 & 3 & 5 & 9 & 36 & 13 & 7 & 4 & 2 & 1 & 275 & 0.56 \\
\hline Tragedy & 145 & 8 & 3 & 9 & 31 & 12 & 4 & 9 & 4 & 0 & 225 & 0.46 \\
\hline Suffering & 30 & 7 & 10 & 16 & 60 & 35 & 5 & 47 & 4 & 0 & 214 & 0.43 \\
\hline Macabre & 134 & 2 & 1 & 6 & 0 & 2 & 0 & 4 & 0 & 1 & 150 & 0.30 \\
\hline Disaster & 59 & 0 & 5 & 2 & 5 & 1 & 0 & 9 & 2 & 1 & 84 & 0.17 \\
\hline Catastrophe & 26 & 1 & 0 & 4 & 4 & 3 & 0 & 1 & 2 & 0 & 41 & 0.08 \\
\hline Genocide & 15 & 4 & 2 & 0 & 0 & 2 & 0 & 0 & 0 & 0 & 23 & 0.05 \\
\hline Battlefield & 9 & 0 & 1 & 0 & 0 & 1 & 0 & 0 & 0 & 0 & 11 & 0.02 \\
\hline Atrocity & 6 & 0 & 0 & 0 & 0 & 0 & 0 & 2 & 0 & 0 & 8 & 0.02 \\
\hline Totals & $\underline{\underline{13266}}$ & $\underline{4512}$ & 3149 & $\underline{\underline{5468}}$ & $\underline{\underline{4298}}$ & $\underline{775}$ & $\underline{\underline{2820}}$ & $\underline{\underline{11689}}$ & 3076 & 167 & 49220 & $\underline{100.00}$ \\
\hline
\end{tabular}

The frequency data was analysed using chi-square to test the null hypothesis that there was no statistically significant association between total dark word count and city category. The tests compared the observed total dark word count for each city category with totals expected 
under the null hypothesis, under the assumption that totals amongst city categories would be equal if the null hypothesis was correct. The results of the chi-square test is shown in table 5.

Table 4 - Chi-squared analysis

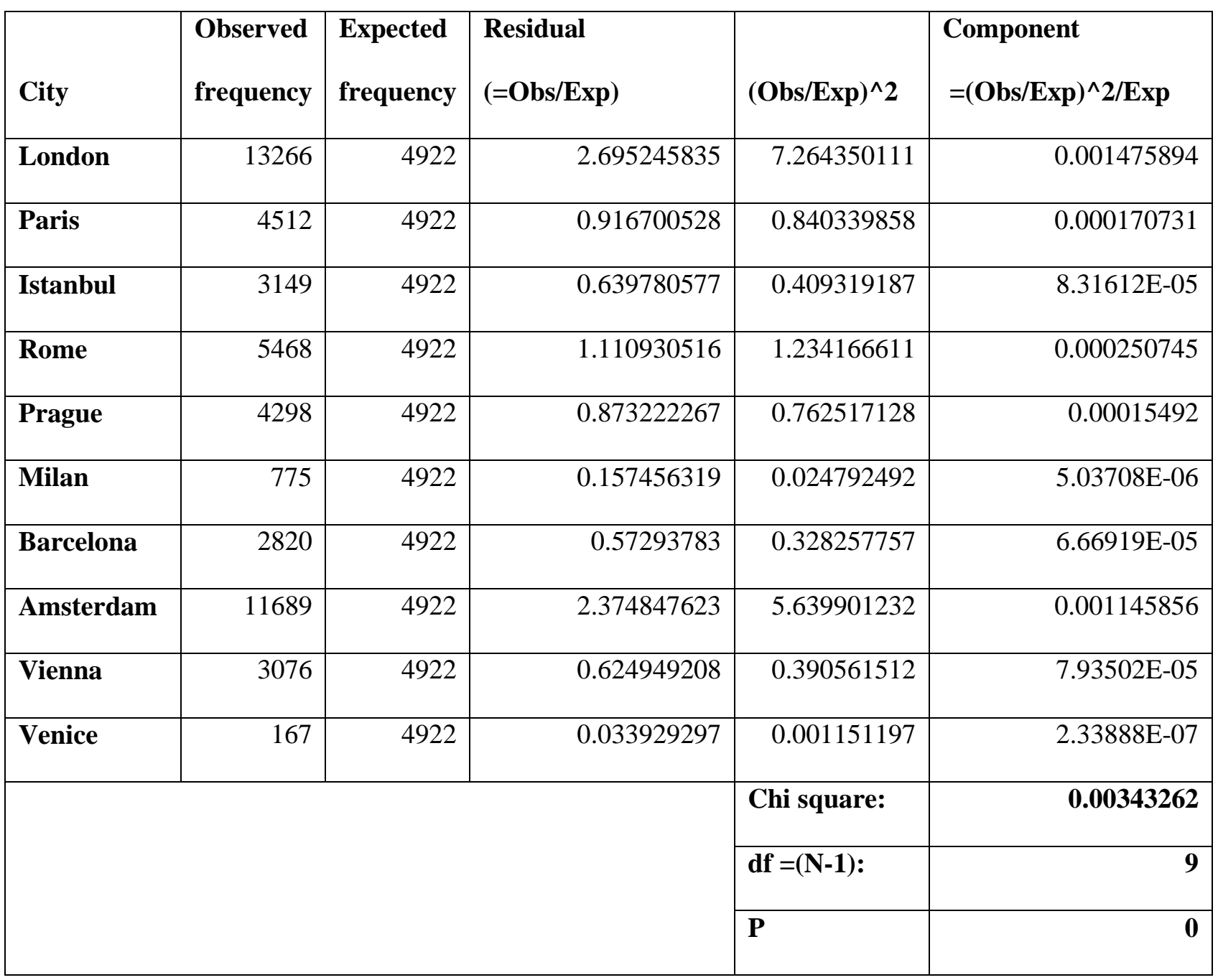

Since $\mathrm{P}<0.001$, the null hypothesis is rejected, and a conclusion is made that there is a significant association between total dark word count and city category, meaning that it was possible to construct a ranking of Europe's top ten most visited tourism cities in terms of the darkness of the tourism products and services that were present on their DMO websites, creating a darkness index of Europe's top tourism cities. This index is shown in table 6, below. 


\begin{tabular}{|l|l|r|}
\hline Ranking & City & \multicolumn{1}{|c|}{} \\
\hline 1st & London & 13266 \\
\hline 2nd & Amsterdam & 11689 \\
\hline 3rd & Rome & 5468 \\
\hline 4th & Paris & 4512 \\
\hline 5th & Prague & 4298 \\
\hline 6th & Istanbul & 3149 \\
\hline 7th & Vienna & 3076 \\
\hline 8th & Barcelona & 2820 \\
\hline 9th & Milan & 775 \\
\hline 10th & Venice & 167 \\
\hline
\end{tabular}

\section{Discussion}

The results presented above describe the extent to which words associated with dark tourism products and services on the websites of DMOs, which indicates the extent to which dark tourism is part of the tourist offering of each destination. Although this approach involves some limitations, discussed below, the systematic way in which it has been applied gives an indication of the relative significance of dark tourism in the promotional strategies of each DMO. As described in the methods section, above, the deductive process of keyword searching and the generation of descriptive statistics was then followed by an inductive process of analysis to explain the results in greater detail. This discussion section presents analysis of two key areas of the results: the variation within the sample and the differences between the ranking of the cities by visitor numbers and by darkness. 
Table 5 shows the ranking of Europe's most visited cities by darkness, indicated by the frequency at which the selected keywords appeared on their DMO websites. Within this, there is a wide variation in the frequency of keywords. In this discussion, the two highest and two lowest ranked cities are analysed in more depth, in order to establish the validity of the results above. The highest ranked city, London ( $f=11689)$, receives a frequency seventy-nine times greater than the lowest ranked city, Venice ( $f=167)$. As Powell \& Iankova (2015) explain, London offers an 'entertainment-focused dark tourism experience' through the promotion of a number of high volume attractions such as The London Dungeons and Madame Tussaud's Chamber of Horrors. Although London does contain numerous sites of dark history, it is the presence of these entertainment-focused attractions on the Visit London website that accounts for the high frequency of keywords associated with dark tourism. This research confirms Powell \& Iankova’s (2015) previous findings that London offers a highly commercialised dark tourism product to tourists.

The second highest ranked city in these results is Amsterdam, with 11, 689 instances of dark tourism keywords featuring on the DMO website. Further analysis shows that although Amsterdam does not contain the range of inauthentic dark tourism attractions that can be found in London, the DMO promotes a variety of experiences that could be placed on the dark tourism spectrum (Stone 2006). These experiences include the Anne Frank House, a museum associated with the occupation of the Netherlands during the Second World War, the Slavernijmonument, a monument commemorating the slavery associated with the Netherland's colonial past, and a guide to the 'haunted' locations in the city connected to historical executions, dungeons, robbery and famous deaths. Complicating this analysis, the city is characterised by many heritage and other cultural attractions described using the word dark because of, for example, they are lacking windows at street level to protect from 
flooding, or because of the prevailing painting style of the later Dutch Masters. (Iamsterdam 2017). Both of the highest-ranked cities included in the sample used for this research demonstrate the complexity involved in categorising dark tourism products in terms of their authenticity as dark sites (Miles 2002, Stone 2005, 2006, Brown 2013, Famaki 2013, Johnson 2015).

The two lowest-ranked cities shown in table 5 are Milan $(f=775)$ and Venice $(f=167)$. Both of these cities are associated with significantly low frequency of keywords associated with dark tourism on their DMO websites. Milan is one of Italy’s top international tourist destinations (Euromonitor 2017) and is regarded as one of the country's 'art cities', along with Turin, Venice, Bologna, Ferrara, Florence, Perugia, Rome, Naples and Palermo (Italia 2017). Its prominence as a cultural tourism destination and its worldwide reputation for its fashion industry (de Carlo et al 2009) perhaps explain the lack of attention given to the presentation of dark tourism products on the DMO website. In addition, significant resources that could be used to develop a dark tourism offering are associated with dissonant heritage (Lemelin 2013) related to periods of recent conflict in the city, including the occupation of Northern Italy by Nazi troops and the public hangings of the Italian Dictator, Benito Mussolini and other Fascist leaders in 1945. As Stone (2005) identifies, political factors on the supply-side can have a significant influence over whether a dark site is developed for as a tourism attraction.

Venice is the third most popular tourist city in Italy and the tenth most visited city in Europe (Euromonitor 2017). It is a major international tourism destination for cruise holiday, in particular, and has been a feature of European tourism since the days of the Grand Tour 
(Verhoeven 2013). Unlike Milan, neighbouring destination in Northern Italy, Venice has not been caught up in historical conflicts and although it was occupied during World War Two, it was never bombed, preserving its significant architecture and unique canal-based infrastructure, which has become the main resource for its contemporary tourism. Venice does have some heritage resources that could be incorporated into a dark tourism offer for tourists, including the prisons of the Doge’s Palace and the Catacombs (Venice Tourism 2017), these are associated mainly with very localised events and the individual tragedies of the criminal justice system, and lack broad tourist appeal. The dominant narratives that form Venice’s tourism brand are linked to its cultural and natural heritage (Manrai et al 2017) and its reputation as 'the city of love'. Dark tourism does not fit into this brand and unsurprisingly, words associated with darkness do not feature strongly on its DMO website. This support's Biran et al's (2011) view that supply-side factors are the most important factor in creating dark tourism destinations.

Table 6, below, shows the differences between Europe's most visited tourist cities in terms of visitors and darkness. Although this research has not considered causal relationships, it appears that there is no obvious link between the promotion of dark tourism and the success of a destination in attracting tourists. This descriptive analysis suggests that, for some destinations, the promotion of darkness may be associated with lower visitor numbers, although this requires further investigation. 


\begin{tabular}{|l|r|r|r|}
\hline City & ranking & index & Difference \\
\hline London & 1 & 1 & $=0$ \\
\hline Paris & 2 & 5 & -3 \\
\hline Istanbul & 3 & 8 & -5 \\
\hline Rome & 4 & 6 & -2 \\
\hline Prague & 5 & 7 & -2 \\
\hline Milan & 6 & 9 & -3 \\
\hline Barcelona & 7 & & \\
\hline Amsterdam & 8 & & +3 \\
\hline Vienna & 9 & & \\
\hline Venice & 10 & & \\
\hline
\end{tabular}

\section{Conclusions}

This paper has investigate the relationship between city tourism and dark tourism in a European context, through the analysis of the websites of the DMOs of Europe's top ten most visited tourist cities. In order to do this, the literature on dark tourism and tourist cities was reviewed, and nineteen keywords were identified from this, related to dark tourism. A search was carried out on DMO websites for the frequency of these words, and the variation in these totals was tested for statistical significance using the chi-squared test. The variation within this sample was found to be significant, and a new index of these cities was created, which ranked them in terms of the significance of their dark tourism offer for tourists. 
The approach taken in this paper presents a number of limitations that can be explored in further research. Firstly, the keywords shown in table 2 were chosen following the literature review presented in this paper. Certain prospective keywords were eliminated from this list, however this process was completed in a rigorous but not systematic way. Because of this, an element of subjectivity was inherent in the selection process. Future research applying this method should conduct a systematic review of the literature and consider using software to aid this selection process, such as NviVo or emerging semantic analysis tools, to develop a more objective set of keywords to use in content analysis. A second limitation is the small sample size that was chosen for this research. This exploratory paper made use of a purposeful sample of the top ten tourism cities in Europe, but now that this methodology has been developed, the study could be repeated using the full Euromonitor (2017) list of all major European tourist cities, or extended to a global list of tourism cities. This would allow for the construction of a more extensive index of darkness for tourism cities. The third limitation of this study has been explored in the discussion section above. This paper has only considered the presentation of dark tourism product and services within DMO websites, in English. Because of this, specific DMO marketing campaigns were excluded from the analysis, which might give an alternative measure of DMO promotional activity. In addition, only international-focused websites were analysed, that are presented in the English language, which might miss activity related to developing dark tourism products and services for the domestic tourism market.

This research has confirmed the prevailing view in the literature that there are differences of emphasis on the supply-side of dark tourism, and that the idea of a scale of darkness that has been applied to dark tourism products (Lennon \& Foley 2000, Raine 2013, Stone 2005, Strange \& Kempa 2003) can also be applied to the classification of cities as dark tourism 
destinations. Biran et al (2011) and Yan et al (2016) draw attention to the key role played by the supply-side of dark tourism in determining whether a site can be developed for dark tourism. The four examples of cities discussed above (London, Amsterdam, Milan and Venice), show how supply-side issues of varying kinds, such as the authenticity of the offer, the number of dark attractions, the dominant brand of a destination and the presence of dissonant heritage can impact on the ranking of a city on the darkness index.

For practitioners in tourist city marketing, tourism marketing and destination management, this research shows that there is a wide variation between European cities in terms of the promotion of dark tourism products and services as part of their tourist offer. This suggest product development and marketing opportunities for cities that wish to capture the emerging dark tourism market. A more developed and comprehensive dark tourism index of tourist cities can be used by practitioners to evaluate their success in promoting this aspect of their city's tourism offer and to judge their performance against competitor destinations. 


\section{References}

Banks, I., \& Pollard, T. (2011). Protecting a bloodstained history: battlefield conservation in Scotland. Journal of Conflict Archaeology, 6(2), 124-145.

Berg, B. (2007) Qualitative Research Methods for the Social Sciences, London: Sage

Biran,A.,Poria, Y.,Oren, G.(2011) SOUGHT EXPERIENCES AT (DARK) HERITAGE

SITES, Annals of Tourism Research, Volume 38, Issue 3, July 2011, Pages 820-841.

Blom, T. (2000), “'Morbid tourism - a postmodern market niche with an example from Althorp’,Norsk Geografisk Tidsskrift, Vol. 54 No. 1, pp. 29-36.

Brown, J. (2013) Dark tourism shops: selling “dark” and“'difficult”’ products. International Journal of culture and Touism and Hospitality Research, VOL. 7 NO. 3 2013, pp. 272-280.

Bryman, A. \& Bell, E. (2007) Business Research Methods, Oxford: Oxford University Press

Collins-Kreiner, N. (2016). Dark tourism as/is pilgrimage. Current Issues in Tourism, 19(12), 1185-1189.

Crompton, J. L. (1979). Motivations for pleasure vacation. Annals of tourism research, 6(4), 408-424.

Dale, C., \& Robinson, N. (2011), “Dark Tourism”, in Robinson, P., Heitmann, S., \& Dieke, P. (Eds). Research Themes for Tourism, 38(1), pp 193-209. 
Dann, G.M., 1998. The dark side of tourism. CIRET-International Center for Research and Studies in Tourism.

De Carlo, M., Canali, S., Pritchard, A., \& Morgan, N. (2009). Moving Milan towards Expo 2015: designing culture into a city brand. Journal of Place Management and Development, 2(1), 8-22.

Euromonitor (2017) Top 100 City Destinations Ranking, London, Euromonitor

Farmaki, A., (2013),"Dark tourism revisited: a supply/demand conceptualisation", International Journal of Culture, Tourism and Hospitality Research, Vol. 7 Iss 3 pp. 281 292.

Hyde, K.F. and Harman, S. (2011), “Motives for a secular pilgrimage to the Gallipoli battlefields”,Tourism Management, Vol. 32, pp. 1343-1351.

Gale, T. (2005) 'Modernism, Post-modernism and the Decline of British Seaside Resorts as Long Holiday Destinations: A Case Study of Rhyl, North Wales' in Tourism Geographies, Vol. 7, No.1, pp.86-112

Hoffman, L. (2003) 'The Marketing of Diversity in the Inner City: Tourism and Regulation in Harlem' in International Journal of Urban and Regional Research, Vol.27, No.2, pp.286-99 
Hyde, K.F. and Harman, S. (2011), “Motives for a secular pilgrimage to the Gallipoli battlefields”,Tourism Management, Vol. 32, pp. 1343-1351.

Iamserdam (2017) ‘Things to do’ [online\}

Available from: https://www.iamsterdam.com/en/see-and-do/things-to-do/

Accessed $12^{\text {th }}$ September 2017

Johnston, T,. (2015) The geographies of thanatourism. Geography Vol 100 Part 1 Spring 2015.

Kang, E.J., Scott, N., Lee, T.J. and Ballantyne, R. (2012), “'Benefits of visiting a dark tourism site: the case of the Jeju April 3rd Peace Park, Korea’, Tourism Management, Vol. 33, pp. 257-265.

Lee, C. K., Bendle, L. J., Yoon, Y. S., \& Kim, M. J. (2012). Thanatourism or peace tourism: Perceived value at a North Korean resort from an indigenous perspective. International Journal of Tourism Research, 14(1), 71-90.

Harvey Lemelin, R., Powys Whyte, K., Johansen, K., Higgins Desbiolles, F., Wilson, C., \& Hemming, S. (2013). Conflicts, battlefields, indigenous peoples and tourism: addressing dissonant heritage in warfare tourism in Australia and North America in the twenty-first century. International Journal of Culture, Tourism and Hospitality Research, 7(3), 257-271. Italia (2017) ‘Art Cities’ [online] 
Available from: http://www.italia.it/en/travel-ideas/art-cities.html

Accessed $13^{\text {th }}$ September 2017

Lennon, J., \& Foley, M. (2000). Dark Tourism: the attraction of death and disaster, Thomson, London.

Light, D. (2017) 'The undead and dark tourism: Dracula tourism in Romania', in G. Hooper and J.J. Lennon (eds) Dark Tourism: Practice and Interpretation, Routledge, Abingdon, 121133

Manrai, L. A., Manrai, A. K., \& DeLuca, J. (2017). Twenty Shades of Italy: An Analysis of its Cultural, Natural, and Dual Tourist Attractions with Implications for Global Tourism Marketing. Journal of Global Marketing, 1-12.

Miles, W.F.S. (2002), “Auschwitz: museum interpretation and darker tourism”, Annals of Tourism Research, Vol. 29, pp. 1175-1178.

Podoshen, J. S. (2013). Dark tourism motivations: Simulation, emotional contagion and topographic comparison. Tourism Management, 35, 263-271.

Podoshen, J. S., Andrzejewski, S. A., Venkatesh, V., \& Wallin, J. (2015). New approaches to dark tourism inquiry: A response to Isaac. Tourism Management, 51, 331-334.

Poon, A. (1994). The 'new tourism'revolution. Tourism management, 15(2), 91-92.

Raine, R. (2013). A dark tourist spectrum. International Journal of Culture, tourism and hospitality Research, 7(3), 242-256 
Powell, R., and Iankova, K. (2015) Dark London: Dimensions and characteristics of dark tourism supply in the UK capital. Anatolia: An International Journal of Tourism and Hospitality Research. ISSN 1303-2917 (Print), 2156-6909 (Online) (In Press)

Richards, G. (ed.) (2007) Cultural Tourism: Global and Local Perspectives, New York: Haworth Press

Richards, G. \& Wilson, J. (2007) 'The Creative Turn in Regeneration: Creative Spaces, Spectacles and Tourism in Cities' in Smith, M. (ed.) Tourism Culture and Regeneration, Wallingford: CABI, pp. 12-24.

Rittichainuwat, N. (2008). Responding to disaster: Thai and Scandinavian tourists' motivation to visit Phuket, Thailand. Journal of Travel Research, 46(4), 422-432.

Rofe, M. W. (2013). Considering the limits of rural place making opportunities: Rural dystopias and dark tourism. Landscape Research, 38(2), 262-272.

Rojek, C. (1993), Ways of Escape, Macmillan, London.

Ryan, C., and Kohli, R., (2006) The Buried village, New Zealand - An example of dark tourism? Asia Pacific Journal of Tourism Research Vol. 11 , Iss. 3.

Seaton, A.V. (1996). “Guided by the dark: from thanatopsis to thanatourism”, International Journal of Heritage Studies, 2(4), pp.234-244.

Seaton, A. V. \& Lennon, J. J. (2004) : New horizons in tourism: strange experiences and stranger practices, Editor : Singh, T. V. pp.63-82, CABI Publishing, Wallingford. 
Seaton, A. (2009), “'Purposeful otherness: approaches to the management of thanatourism”, in Sharpley, R. and Stone, P. (Eds), The Darker Side of Travel: The Theory and Practice of Dark Tourism, Channel View Publications, Bristol, pp. 75-108.

Selby, M. (2004) Understanding Urban Tourism, London: IB Tauris

Sharpley, R. and Stone, P. (2009), The Darker Side of Travel: The Theory and Practice of Dark Tourism, Channel View Publications, Bristol.

Sharpley, R. (2009), “Shedding light on dark tourism: theories and concepts”, in Sharpley, R. and Stone, P. (Eds), The Darker Side of Travel: The Theory and Practice of Dark Tourism, Channel View Publications, Bristol, pp. 3-22.

Shondell Miller, D., \& Gonzalez, C. (2013). When death is the destination: the business of death tourism-despite legal and social implications. International Journal of Culture, Tourism and Hospitality Research, 7(3), 293-306.

Smith, M. (2007) 'Space, Place and Placelessness in the Culturally Regenerated City' in Richards, G. (ed.) Cultural Tourism: Global and Local Perspectives, New York: Haworth Press, pp. 91-108

Smith, V. (1998). “War and tourism: an American ethnography”. Annals of Tourism Research, 25, 202-227 
Smith, N. and Croy,W.G. (2005), " Presentation of dark tourism: TeWairoa, the Buried Village’’, in Ryan, C., Stone, P. and Sharpley, R (2008) Consuming dark tourism: A Thanatological Perspective, Annals of Tourism Research, Volume 35, Issue 2, April 2008, Pages 574-595.

Spirou, C. (2007) 'Cultural Policy and Urban Restructuring in Chicago' in Smith, M. (ed.) Tourism Culture and Regeneration, Wallingford: CABI, pp. 123-131

Stone, P. (2005), “Review: Dark Tourism - cashing in on tragedy?”, paper presented at the Tourism Society Seminar Event, 17 October, London, available at: www.dark-tourism.org.uk (accessed 06 September 2013).

Stone, P. (2006). “A Dark Tourism spectrum: towards a typology of death and macabre related tourist sites, attractions and exhibitions”, Tourism ,54(2), pp. 145-160

Stone, P. R. (2012). Dark tourism and significant other death: Towards a model of mortality mediation. Annals of Tourism Research, 39(3), 1565-1587.

Stone, P. (2013). Dark tourism scholarship: A critical review. International Journal of Culture, Tourism and Hospitality Research, 7(3), 307-318.

Stone, P. and Sharpley, R (2008) Consuming dark tourism: A Thanatological Perspective, Annals of Tourism Research, Volume 35, Issue 2, April 2008, Pages 574-595.

Strange, C., \& Kempa, M. (2003). "Shades of Dark Tourism: Alcatraz and Robben Island” Annals of Tourism Research, 30(2) pp.386-405. 
Taylor, P. A. (2006). Getting them to forgive and forget: Cognitive based marketing responses to terrorist acts. International Journal of Tourism Research, 8(3), 171-183.

Times of Israel (2016) Over 1.7 million visit Auschwitz, breaking Annual Record [online] Available from: http://www.timesofisrael.com/over-1-7-million-visit-auschwitz-breakingannual-record/ (accessed 04/03/2017)

Urry, J. (2002) The Tourist Gaze $2^{\text {nd }} e d$., London: Sage

Van den Berg, L., J. van der Borg and J. van der Meer (1995), Urban Tourism; Performance and strategies in eight European cities, Euricur Series, Ashgate, Aldershot

van Rijnsoever, F. J. (2017). (I Can’t Get No) Saturation: A simulation and guidelines for sample sizes in qualitative research. PLoS One, 12(7), e0181689.

Vellas, F. \& Becherel, L. (1995), International Tourism, Belhaven, London.

Venice Tourism (2017) ‘Places’ [online]

Available from: http://www.venice-tourism.com/en/places

Accessed $13^{\text {th }}$ September 2017

Verhoeven, G. (2013). FORESHADOWING TOURISM: Looking for modern and obsolete features-or some missing link-in early modern travel behavior (1675-1750). Annals of Tourism Research, 42, 262-283. 
Walter, T. (2009), “Disaster, modernity, and the media” in Garces-Foley, K. (Ed), Death and Religion in a Changing World, M.E. Sharpe, Armonk, NY.

Winter, C. (2011). Battlefield visitor motivations: Explorations in the Great War town of Ieper, Belgium. International Journal of Tourism Research, 13(2), 164-176.

Yan, B. J., Zhang, J., Zhang, H. L., Lu, S. J., \& Guo, Y. R. (2016). Investigating the motivation-experience relationship in a dark tourism space: A case study of the Beichuan earthquake relics, China. Tourism Management, 53, 108-121.

Zukin, S. (1995) The Cultures of Cities, Blackwell, Oxford. 